Article

\title{
Time Trends and Factors Associated with Antibiotic Prescribing in Swiss Primary Care (2008 to 2020)
}

\author{
Nahara Anani Martínez-González ${ }^{1,2, *}$ (D) Stefania Di Gangi ${ }^{1}$, Giuseppe Pichierri ${ }^{1}{ }^{10}$, \\ Stefan Neuner-Jehle ${ }^{1}$, Oliver Senn ${ }^{1}$ (D) and Andreas Plate ${ }^{1}$ (D) \\ 1 Institute of Primary Care, University of Zurich and University Hospital of Zurich, Pestalozzistrasse 24, \\ CH-8091 Zurich, Switzerland; stefania.digangi@usz.ch (S.D.G.); giuseppe.pichierri@usz.ch (G.P.); \\ stefan.neuner-jehle@usz.ch (S.N.-J.); oliver.senn@usz.ch (O.S.); andreas.plate@usz.ch (A.P.) \\ 2 Department of Health Sciences and Medicine, University of Lucerne, Frohburgstrasse 3, PO Box 4466, \\ CH-6002 Lucerne, Switzerland \\ * Correspondence: nahara.martinez@usz.ch
}

Received: 2 November 2020; Accepted: 20 November 2020; Published: 23 November 2020

check for updates

\begin{abstract}
Antibiotic resistance (ABR) is a major threat to public health, and the majority of antibiotics are prescribed in the outpatient setting, especially in primary care. Monitoring antibiotic consumption is one key measure in containing ABR, but Swiss national surveillance data are limited. We conducted a retrospective cross-sectional study to characterise the patterns of antibiotic prescriptions, assess the time trends, and identify the factors associated with antibiotic prescribing in Swiss primary care. Using electronic medical records data, we analysed 206,599 antibiotic prescriptions from 112,378 patients. Based on 27,829 patient records, respiratory $(52.1 \%)$, urinary $(27.9 \%)$, and skin $(4.8 \%)$ infections were the commonest clinical indications for antibiotic prescribing. The most frequently prescribed antibiotics were broad-spectrum penicillins (BSP) (36.5\%), fluoroquinolones (16.4\%), and macrolides/lincosamides (13.8\%). Based on the WHO AWaRe classification, antibiotics were $57.9 \%$ Core-Access and $41.7 \%$ Watch, $69 \%$ of which were fluoroquinolones and macrolides. Between 2008 and 2020, fluoroquinolones and macrolides/lincosamides prescriptions significantly declined by $53 \%$ and $51 \%$; BSP prescriptions significantly increased by $54 \%$. Increasing patients' age, volume, and employment level were significantly associated with antibiotic prescribing. Our results may inform future antibiotic stewardship interventions to improve antibiotic prescribing.
\end{abstract}

Keywords: antibiotic prescriptions; antibiotic prescribing; antibiotic use; primary care; general practice; family medicine; outpatient care; ambulatory care; Switzerland

\section{Introduction}

Antibiotic resistance (ABR) and its consequences have escalated into a serious threat to public health globally [1,2]. A key modifiable driver of the accelerated spread of ABR is the irrational consumption of antibiotics in general, and the (excessive) use of broad-spectrum antibiotics in particular [3-5]. While the largest volume of antibiotics used in humans is prescribed in outpatient care, $80-90 \%$ of such prescriptions are issued by general practitioners (GP), and up to $50 \%$ of these prescriptions are inappropriate $[3,5,6]$. This excessive antibiotic prescribing comprises a large amount of overall antibiotic use, and it is a major challenge to healthcare systems [7]. Despite government calls and implementation of guidelines, both the global patterns of antibiotic prescribing and the rates of antibiotic consumption in high-income countries have suffered little change over the past years [7-9].

One of the top five priorities of the European Center for Disease Prevention and Control (ECDC) and the WHO global action plan to optimise the use of antimicrobials includes gathering data on antibiotic resistance and consumption to improve surveillance as a central element in containing ABR $[8,10,11]$. 
Several strategies matching these objectives have established the platforms to monitor resistance and consumption $[8,12,13]$. Generating knowledge about these patterns can help in determining the appropriateness of antibiotic use. At the local and national levels, this knowledge is crucial to inform the design, implementation and monitoring of antibiotic stewardship, the goal of which is to optimise patient safety and outcomes [14]. As primary care continues to exceed the rates of antibiotic use in hospital care, addressing knowledge gaps about the extent of antibiotic consumption in primary care is of an utmost priority.

Antibiotic consumption in the outpatient care setting in Switzerland is lower than in many of the European countries collaborating in the project of the European Surveillance of Antibiotic Consumption (ESAC) by the ECDC [15-17]. It is unclear, however, how much of the prescribing corresponds to primary care only. At the national level, there is no database that allows a systematic collection of data to monitor disease-specific antibiotic consumption in primary care-as yet.

In Switzerland, the Federal Office of Public Health (FOPH) and the Swiss Centre for Antibiotic Resistance (ANRESIS) collect antibiotic consumption data both from the inpatient and outpatient settings [15]. The Swiss surveillance for the outpatient setting feeds from datasets of pharmacies and self-dispensing physicians, or only pharmacies [15]. The outpatient setting, however, comprises services provided on an ambulatory basis including, but not limited to, primary and specialised care. Currently, national surveillance data do not distinguish between these settings. Swiss primary care encompasses about $45 \%$ of the outpatient care sector [18]. Research shows that there can be substantial differences in the rates of antibiotic prescribing between outpatient care services, e.g., primary care, out-of-hours care or specialised care $[19,20]$. Further categorisation by outpatient services in the Swiss surveillance data would be ideal for assessing these differences properly.

Primary research on the study of antibiotic consumption in Swiss primary care is also limited. A few observational studies have provided some insights into the prevalence, predictors or quality of antibiotic prescribing in Swiss primary care, but these focused on specific clinical indications or a specific type (e.g., low or high) of prescribers [21-25].

We aimed to characterise the patterns of antibiotic prescriptions, assess the time trends of these patterns, and identify the factors associated with antibiotic prescribing in Swiss general practice using electronic medical records (EMR) fed by a network of GPs. The EMRs are part of a database project for research in family medicine currently running in German-speaking areas of Switzerland and has so far aggregated patient health routine data over 12 years [26].

\section{Results}

We identified a total of 155,292 patients with antibiotic prescriptions (Figure 1). Eligible data for our analyses comprised 112,378 individual patients with 206,599 prescriptions of systemic antibiotic. The patients' mean age was 52.9 (SD 20.5; range: $18-100)$ years, and $60 \%(n=67,439)$ were women. The overall mean number of antibiotic prescriptions per patient was 1.65 (range: 1-28, SD 1.28). Overall, regardless of clinical indications, more antibiotics were prescribed in women compared to men (mean no.: 1.71 (SD 1.29) vs. 1.57 (SD 1.07; $p<0.001$ ).

Prescribing data by the canton of practicing GPs were available for $96.0 \%(198,272)$ of the prescriptions. Of these, $99.8 \%(n=197,949)$ of the prescriptions were issued in the German-speaking areas, including cantons of different languages but where German is officially the dominant language. The other $0.2 \%(n=323)$ of the prescriptions were issued in cantons where French is officially the dominant language.

\subsection{Patterns of Antibiotic Prescriptions}

Broad-spectrum penicillins (BSP) were the most common class of antibiotics used, accounting for $36.5 \%(n=75,534)$ of the prescriptions among all classes (Table 1$)$. Amoxicillin plus beta-lactamase inhibitors (BLI) were the most frequently prescribed antibiotics both within this class and overall accounting for $29.8 \%(n=61,733)$ of all prescriptions (see Supplementary Materials). Fluoroquinolones 
and macrolides/lincosamides were the second and third most common classes of antibiotics accounting for $16.4 \%(n=33,900)$ and $13.8 \%(n=28,589)$ of the prescriptions, respectively. The most frequently prescribed antibiotics within these classes were ciprofloxacin and clarithromycin, accounting for $10.5 \%$ ( $n=21,770)$ and $7.1 \%(n=14,633)$ of the antibiotic prescriptions, respectively. Based on the WHO Aware classification, 57.9\% $(n=119,649)$ of all prescriptions were "Access" antibiotics, $41.7 \%(n=86,142)$ were "Watch" antibiotics, and 0.02\% $(\mathrm{n}=48)$ were "Reserve" antibiotics.

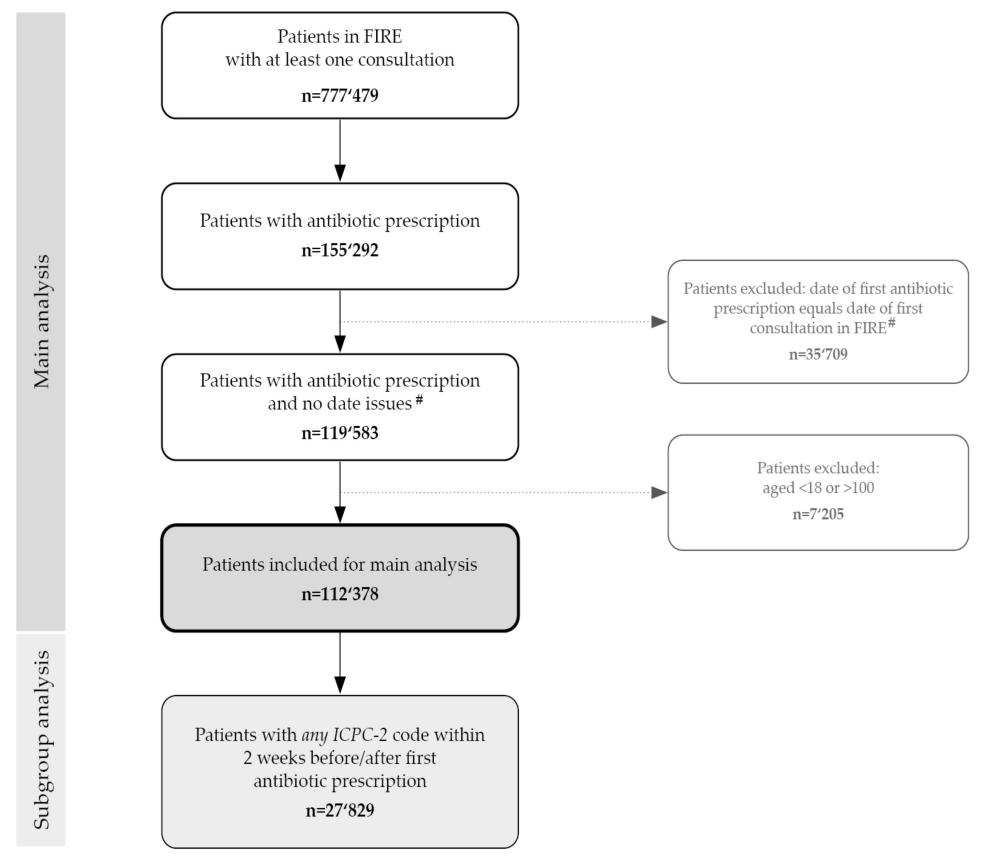

Figure 1. Event flow chart. Number of patients with antibiotic prescriptions in Swiss primary care from the FIRE database. FIRE, Family Medicine ICPC-Research using EMR; EMR, Electronic Medical Records; ICPC, International Classification of Primary Care (-2) code system. \#Date issues: when the date of a first antibiotic prescription coincided with the date of a first consultation; a prescription could have been carried over from a previous consultation prior to the patient's inclusion in the database.

The distribution of antibiotic prescribing significantly changed over twelve years, from 2008 to 2020 (Figure 2a). Prescriptions of BSP and "other antibacterials" (WHO Anatomical Therapeutic Chemical Classification System (ATC) class J01XB-J01XX: $>98 \%$ are nitrofurantoin and fosfomycin) significantly increased by 54\% (39.3\% to $25.6 \%$; yearly linear increase: 0.76 points; $p<0.001)$ and almost tripled (3.7\% to $14.1 \%$; linear yearly increase: 1.06 points; $p<0.001)$. At the same time, there was a constant decline in the rates of fluoroquinolone and macrolide/lincosamide. Prescriptions of such antibiotics significantly reduced by $53 \%$ (26.6\% to $12.4 \%$; yearly linear decrease: -1.27 points, $p<0.001)$ and $51 \%$ (26.1\% to $12.8 \%$; yearly linear decrease: -0.67 points, $p=0.004)$ respectively. Tetracyclines show a significant linear increase of $0.07(p=0.006)$ while cephalosporins, intestinal antiinfectives and narrow-spectrum penicillins showed a wide variation but no significant difference in the rates of prescribing ( $p=0.182, p=0.458$ and $p=0.254$ ) over the twelve years (Figure $2 b$ ).

Distribution of antibiotic prescribing showed a significant variation in the number of prescriptions by month $(p<0.001)$ (Figure 3a). There was a non-monotonic trend in the number of prescriptions throughout the year with the summer months showing the lowest rates of antibiotic prescriptions ( $23.4 \%, n=48,417$ for the season). The number of prescriptions increased the most during the cold season (September to December), reaching the highest rates in winter $(28.1 \%, \mathrm{n}=58,060$ for the season).

Fluctuation of antibiotic prescribing by year showed that the year 2013 was the observed peak of antibiotic prescriptions (Figure 3b). From 2008 to 2013, there was a steady, significant quadratic increase of $70 \%$ (yearly quadratic trend: 16.2 to $27.6 ; p=0.008$ ) in the number of antibiotic prescriptions 
per 1000 consultations. From 2013 to 2020, the rate significantly fell by 39\% (yearly quadratic trend: $27.6 \%$ to $16.95 \% ; p=0.008)$ prescriptions per 1000 consultations.

Table 1. Distribution of 206,599 antibiotic prescriptions in 112,378 patients in Swiss primary care for the period 2008-2020.

\begin{tabular}{ccc}
\hline Class Number, $\mathbf{n}$ & Antibiotic Class & Prescriptions, $\mathbf{n}(\mathbf{\%})$ \\
\hline 1 & Broad spectrum penicillins & $75,534(36.5)$ \\
2 & Fluoroquinolones & $33,900(16.4)$ \\
3 & Macrolides, Lincosamides & $28,589(13.8)$ \\
4 & Other antibacterials ${ }^{1}$ & $23,268(11.3)$ \\
5 & Sulfonamides and Trimethoprim & $18,380(8.9)$ \\
6 & Tetracyclines & $9670(4.7)$ \\
7 & Cephalosporins & $7886(3.8)$ \\
8 & Intestinal antiinfectives ${ }^{2}$ & $5364(2.6)$ \\
9 & Narrow spectrum penicillins & $3160(1.5)$ \\
10 & Antimycobacterials & $732(0.4)$ \\
11 & Carbapenems & $53(0.0)$ \\
12 & Glycopeptides & $45(0.0)$ \\
13 & Aminoglycosides & $17(0.0)$ \\
14 & Monobactams & $1(0.0)$ \\
\hline
\end{tabular}

${ }^{1}$ This group consists of drugs in the ATC group J01XB-J01XX; ${ }^{2}$ This group consists of drugs in the ATC groups A07AA and P01AB01. ATC, WHO Anatomical Therapeutic Chemical Classification System codes; n, number.

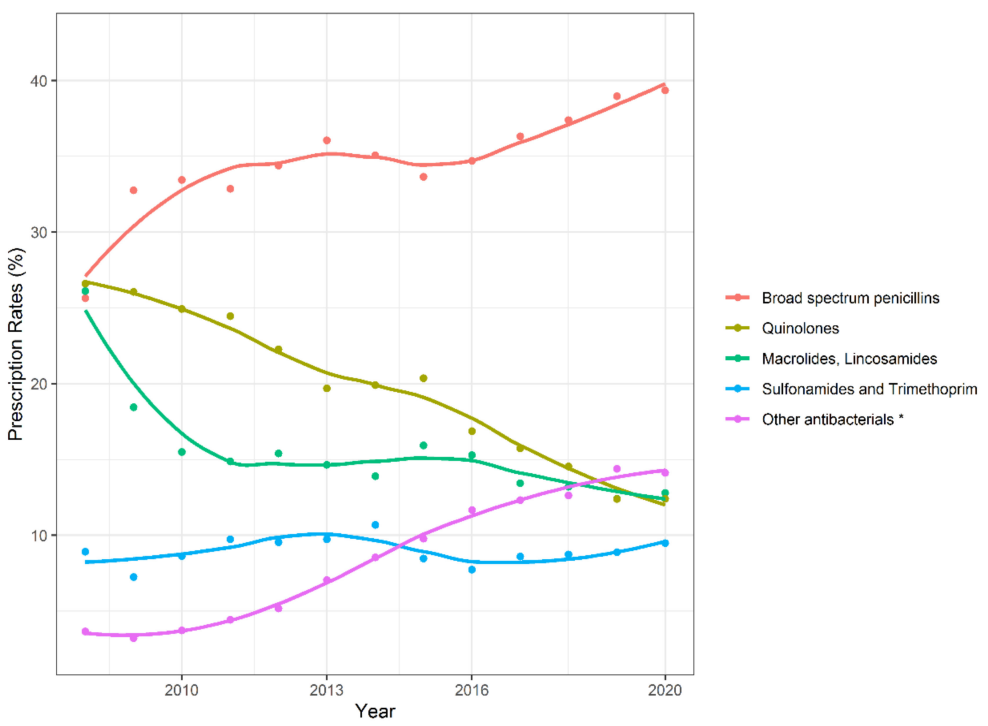

(a)

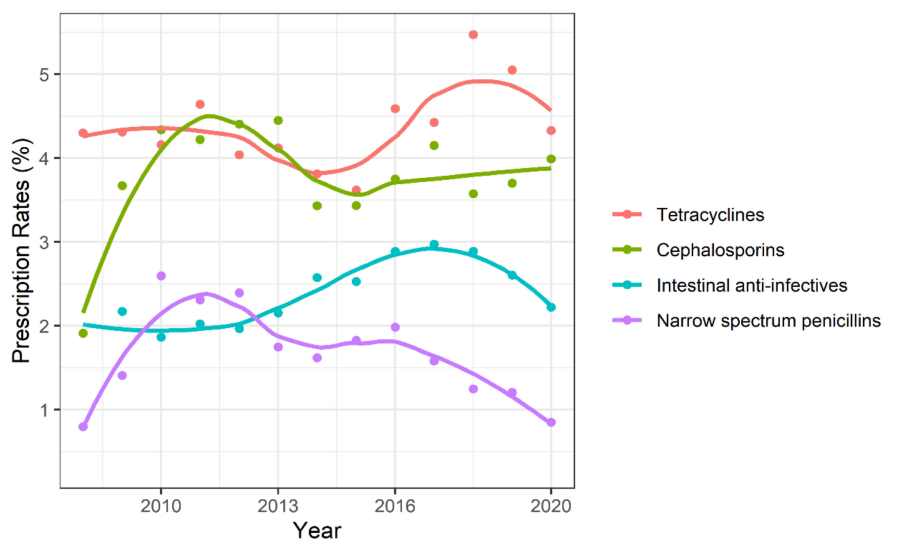

(b)

Figure 2. Time trends in antibiotic prescribing in primary care. Points are yearly observed numbers and lines are smoothed curves. (a) Antibiotics with >10,000 prescriptions; (b) Antibiotics with $>1000$ prescriptions. * This group contains prescriptions from the ATC group J01XB-J01XX. The prescriptions reported in this group consist of $>98 \%$ nitrofurantoin and fosfomycin prescriptions. 


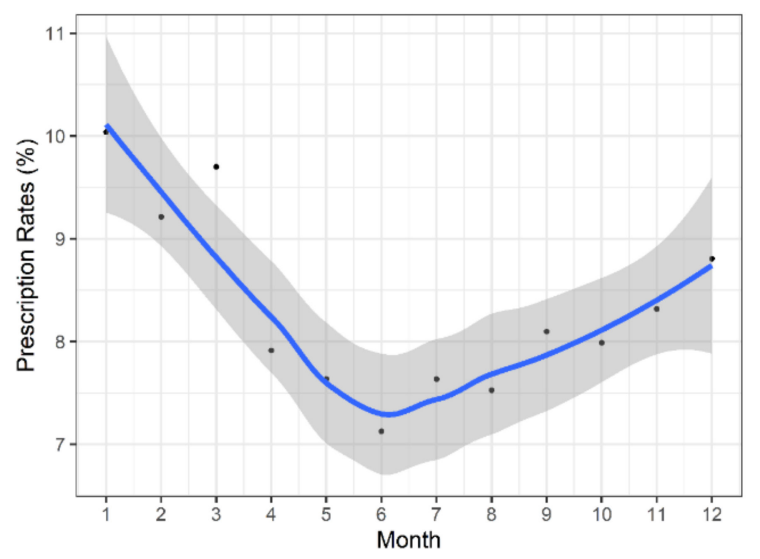

(a)

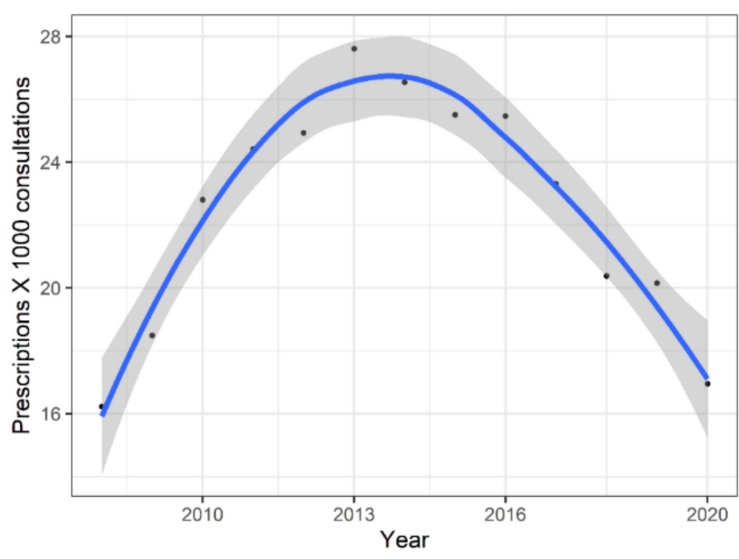

(b)

Figure 3. Distribution of antibiotic prescribing in Swiss primary care. Points are observed numbers and lines are smoothed curves; 95\% Confidence Interval band is shown in grey. (a) Seasonal variation of antibiotic prescriptions by month: 1 = January, 12 = December; (b) Fluctuation of antibiotic prescriptions over 12 years.

\subsection{Subgroup Analysis}

A subgroup of $27,829(24.7 \%)$ patient records contained information by the International Classification of Primary Care 2 (ICPC-2) code system allowing the identification of fifteen clinical indications for which antibiotics were most prescribed. Based on ICPC-2 codes for both general (Table 2) and infectious (Table 3) diseases, respiratory tract infections/symptoms were the most common clinical indication accounting for $52.1 \%(\mathrm{n}=11,039)$ of all antibiotics prescribed among the fifteen indications, followed by urinary tract infections and skin infections with $27.9 \%(n=5898)$ and $4.8 \%(n=1000)$ of the antibiotics prescribed respectively.

The index of inequality in the rate of prescriptions across 240 GPs with 26,595 prescriptions is presented in Figure 4. Quantitative differences among GPs show that 25\% of the GPs with the lowest antibiotic prescribing accounted for $9 \%(n=2303)$ of all prescriptions-the lower quarter. The $25 \%$ of the GPs with the highest prescribing accounted for $43 \%(n=11,436)$ of all prescribed antibiotics-the upper quarter.

Table 2. Top 15 clinical indications for antibiotic prescribing in Swiss primary care.

\begin{tabular}{ccc}
\hline Clinical Indications & ICPC-2 Code $\mathbf{1}^{\mathbf{1}}$ & Prescriptions, $\mathbf{n}$ \\
\hline Respiratory tract & & 11,039 \\
Upper respiratory tract infections & $\mathrm{R} 74$ & 2516 \\
Pneumonia & $\mathrm{R} 81$ & 1777 \\
Acute/chronic sinusitis & $\mathrm{R} 75$ & 1664 \\
Cough & $\mathrm{R} 05$ & 1404 \\
Acute Tonsillitis & R76 & 1271 \\
Acute Bronchitis / Bronchiolitis & R78 & 973 \\
Throat symptoms & R21 & 720 \\
Streptococci pharyngitis & R72 & 714 \\
Urinary tract infection & U71 & 5898 \\
Skin infection & S76 & 1000 \\
Diverticulosis / Diverticulitis & D92 & 971 \\
Abdominal Pain & D06 & 599 \\
Fever & A03 & 571 \\
Insect bite & S12 & 550 \\
Acute otitis media & H71 & 549 \\
\hline
\end{tabular}

\footnotetext{
${ }^{1}$ ICPC-2, International Classification of Primary care 2 code system; $n$, number.
} 
Table 3. Antibiotic prescriptions for infectious diseases by ICPC-2 diagnosis and anatomic groups.

\begin{tabular}{|c|c|c|c|}
\hline Infectious Diseases & ICPC Category $^{1}$ & Overall Prescriptions, $n$ & Overall Prescriptions, $\%$ \\
\hline & & 21,021 & 100 \\
\hline Respiratory & R71-83 & 9968 & 47.4 \\
\hline Urological & U70-72 & 6514 & 31.0 \\
\hline Skin & $\begin{array}{c}\mathrm{S} 03,09-11,70-76,84 \\
95\end{array}$ & 1409 & 6.7 \\
\hline Ear & H70-74 & 926 & 4.4 \\
\hline Digestive system & D70-73 & 847 & 4.0 \\
\hline Male genital & Y70-76 & 503 & 2.4 \\
\hline General and unspecified & A70-78 & 467 & 2.2 \\
\hline Eye & F70-73 & 169 & 0.8 \\
\hline Musculoskeletal & L70 & 78 & 0.4 \\
\hline Female genital & X70-74, 90-92 & 80 & 0.4 \\
\hline Blood, Blood Forming Organs and Immune Mechanism & B70-71 & 29 & 0.1 \\
\hline Cardiovascular & K70-71 & 16 & 0.1 \\
\hline Neurological & N70-73 & 11 & 0.1 \\
\hline Endocrine/Metabolic and Nutritional & T70 & 4 & 0.0 \\
\hline
\end{tabular}

${ }^{1}$ ICPC-2, International Classification of Primary Care 2 code system; n, number.

\subsection{Multivariable and Sensitivity Analyses}

Regression analysis demonstrated a significant correlation between several factors and antibiotic prescribing in the multivariable analysis (Table 4). At the GP level, antibiotic prescribing was significantly and directly associated with an increasing number of GP consultations $(0.281,95 \%$ confidence intervals (CI) 0.163 to $0.398 ; p<0.001$ ), i.e., as the number of consultations increased, the number of prescriptions also increased. Similarly, GPs employed at a level of $<50 \%$ prescribed significantly fewer antibiotics $(-0.279,95 \% \mathrm{CI}-0.507$ to $-0.051 ; p=0.017)$ compared to GPs employed full-time. At the patient level, increasing patient age (units of increase or age: $0.002,95 \%$ CI 0.001 to $0.003 ; p<0.001$ ) and being female (male gender: $-0.234,95 \% \mathrm{CI}-0.272$ to $-0.196 ; p<0.001$ ) were significantly associated with more antibiotic prescriptions. Sensitivity analysis showed, however, that after excluding the sample of patients with ICPC codes available for UTIs, gender was no longer associated with antibiotic prescribing (male gender: $-0.028195 \% \mathrm{CI}-0.111$ to $0.0546, p=0.505$ ). Thus, in our analysis, UTIs were a confounding variable for antibiotic prescribing in women.

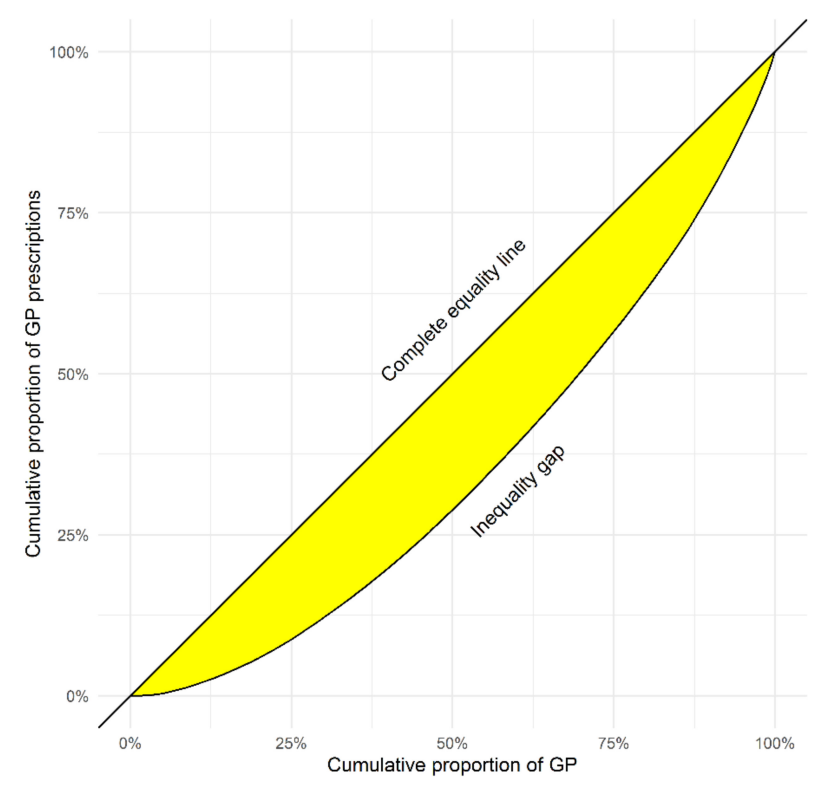

Figure 4. Inequality in prescriptions across Swiss general practitioners: Lorenz curve of antibiotic prescriptions in a subgroup of 240 general practitioners (GPs) with 26,595 antibiotic prescriptions issued in 2018. Index of inequality by Gini's coefficient $=0.31$; “ 0 " = perfect equality (straight line) and " 1 " = total inequality. The further the Lorenz curve deviates from perfect equality, the higher the Gini coefficient and the inequality. 
Table 4. Mixed model regression analysis on antibacterial prescriptions in 2018.

\begin{tabular}{|c|c|c|c|c|c|}
\hline \multirow[t]{2}{*}{$\begin{array}{c}\text { Predictor } \\
\text { (Reference, Where Applicable) }\end{array}$} & \multicolumn{3}{|c|}{ Univariable Analysis } & \multicolumn{2}{|c|}{$\begin{array}{c}\text { Multivariable Analysis } \\
\mathrm{n}=26,589, \mathrm{GPs}=240\end{array}$} \\
\hline & Prescriptions and GPs, $n$ & Estimates (95\% CI) & $p$ & Estimates (95\% CI) & $p$ \\
\hline GP Characteristics & & & & $\mathrm{ICC}=0.09$ & \\
\hline Age & $\mathrm{n}=26,595, \mathrm{GP}=240$ & $0.005(-0.001,0.011)$ & 0.080 & & \\
\hline N. consultations $\geq 6000(<6000)$ & $\mathrm{n}=26,595, \mathrm{GP}=240$ & $0.355(0.252,0.457)$ & $<0.001$ & $0.281(0.163,0.398)$ & $<0.001$ \\
\hline Female gender (male) & $\mathrm{n}=26,595, \mathrm{GP}=240$ & $-0.205(-0.316,-0.094)$ & $<0.001$ & $-0.079(-0.199,0.042)$ & 0.204 \\
\hline Years in practice & $\mathrm{n}=22,808, \mathrm{GP}=204$ & $0.006(-0.0004,0.012)$ & 0.068 & & \\
\hline Self-Employed (employee) & $\mathrm{n}=24,604, \mathrm{GP}=216$ & $0.089(-0.035,0.213)$ & 0.161 & & \\
\hline \multicolumn{6}{|l|}{ Employment level (100\%) } \\
\hline$<50 \%$ & & $-0.483(-0.694,-0.266)$ & $<0.001$ & $-0.279(-0.507,-0.051)$ & 0.017 \\
\hline $50-79 \%$ & $\mathrm{n}=26,595, \mathrm{GP}=240$ & $-0.271(-0.400,-0.143)$ & $<0.001$ & $-0.100(-0.247,0.047)$ & 0.183 \\
\hline $80-99 \%$ & & $-0.096(-0.235,0.044)$ & 0.179 & $-0.058(-0.193,0.077)$ & 0.402 \\
\hline \multirow{2}{*}{\multicolumn{6}{|c|}{$\begin{array}{l}\text { Practice Characteristics } \\
\text { Type of practice (single practice) }\end{array}$}} \\
\hline & & & & & \\
\hline Double practice & $\mathrm{n}=26,595, \mathrm{GP}=240$ & $-0.136(-0.451,0.179)$ & 0.399 & & \\
\hline Group practice & & $-0.086(-0.247,0.075)$ & 0.297 & & \\
\hline \multicolumn{6}{|l|}{ Patient Characteristics } \\
\hline Age & $\mathrm{n}=26,595, \mathrm{GP}=240$ & $0.002(0.001,0.003)$ & $<0.001$ & $0.002(0.001,0.003)$ & $<0.001$ \\
\hline Male gender (female) * & $\mathrm{n}=26,589, \mathrm{GP}=240$ & $-0.231(-0.270,-0.193)$ & $<0.001$ & $-0.234(-0.272,-0.196)$ & $<0.001$ \\
\hline
\end{tabular}

Note. Linear model of number of prescriptions with patient and general practitioners (GPs) characteristics as fixed effects and GPs as random effects (mixed model). $\mathrm{n}$, number; $\mathrm{CI}$, Confidence interval; ICC, Intraclass correlation. *: Sensitivity analyses: after excluding patients with ICPC (International Classification of Primary Care) codes available for urinary tract infections, gender was no longer associated with antibiotic prescribing $(p=0.505)$ 


\section{Discussion}

To the best of our knowledge, our study is the first assessing both the patterns of antibiotic prescribing and its associated factors exclusively in Swiss primary care with a network of GPs as the source of health data. As such, our study contributes by adding data specific to the GP setting, which in national reports is not distinguished from outpatient care [15]. Our study represents a network of GPs working predominantly in the German-speaking areas of Switzerland and a population of adults, the majority of whom were middle-aged and mostly women.

Regardless of the clinical indication, women were more likely to receive antibiotics than men. The three most common clinical indications for antibiotics were, in descending order of frequency, RTIs, UTIs and skin infections. The most frequently prescribed antibiotics were amoxicillin plus BLI, ciprofloxacin and clarithromycin. We found a constant and significant increase in prescriptions of BSP and a significant and steady decline in quinolones prescriptions.

Monitoring antibiotic consumption in both the in- and out-patient settings is of utmost importance as it provides the basis for the implementation and evaluation of antibiotic stewardship interventions. Antibiotic consumption, especially the inappropriate use of antibiotics, is associated with increased rates of ABR [3]. In Europe, nearly 672,000 infections with resistant bacteria were reported in 2015, emphasising the burden of ABR [1]. In the outpatient setting, the distinction between primary and specialised care is critical since prescribing patterns differ significantly, and the majority of antibiotics is prescribed in primary care [19].

Our findings on the most common antibiotic classes used in Swiss primary care are in line with both national and European surveillance programs [15,27]. BSP, fluoroquinolones, macrolides, lincosamides, and tetracyclines are the antibiotic classes most commonly used in the community. The relative order in which these are used might differ across countries. In particular, our study with a focus on primary care shows a distribution of antibiotic use similar to that from the national surveillance, which is based on several outpatient care services [15].

The WHO recently introduced the AWaRe classification to emphasise the importance of the optimal use of antibiotics and their potential for ABR [28]. It recommends using the group of Core-Access antibiotics in a proportion of more than $60 \%$ to reduce ABR while achieving a positive impact on health outcomes. In our study, $58 \%$ of all prescribed antibiotics classified as Core-Access, which is lower than the proportion (65\%) reported in 2018 using Swiss surveillance outpatient health data [15]. The $42 \%$ of Watch antibiotics, of which $69 \%$ were fluoroquinolones and macrolides, surpasses the $25 \%$ reported in 2018. The federal health dataset from the outpatient care setting (specialist and primary care) comprises pharmaceutical sales data and data from pharmacies and self-dispensing physicians. In this dataset, antibiotic prescriptions in primary care are not distinguished from the whole outpatient care setting. Additionally, as the AWaRe classification has evolved, a group of antibiotics initially categorised as "others" (10\%) in the 2018 national report are now grouped into specific categories, which affects their final distribution.

Our study shows a steady decline in the rate of antibiotic prescriptions per 1000 patients, which is consistent with the trends of antibiotic consumption reported by the Swiss national surveillance [15] and western European countries such as Germany, France, the United Kingdom and Belgium [29,30]. In particular, data from the FOPH show a small reduction in antibiotic consumption in outpatient care with a most dramatic fall between 2015 and 2020. Similarly, in our study the decline in antibiotic prescriptions started in 2013, and also appears to coincide with the introduction of the Swiss strategies Smarter Medicine (Choosing Wisely Switzerland) and the Strategy on Antibiotic Resistance (StAR), which were implemented between 2014 and 2015 to optimise antibiotic consumption at national level [31,32]. Although no national data on antibiotic consumption were available for the period 2008-2013, the increase in antibiotic prescribing observed in our study is parallel to that observed for the same period in some European countries from the ESAC project [8].

Our study indicates that RTIs, UTIs, and skin infections are the most common indications for antibiotic prescribing in Swiss primary care. This finding is consistent with previous Swiss and 
international studies evaluating the consumption of antibiotics at the primary care level [15,33-35]. Although we cannot draw direct conclusions on the appropriateness of antibiotic prescribing using our dataset, it is expected that both RTIs and UTIs are, at least to a certain degree, inappropriately treated with antibiotics [21,22]. Especially, RTIs account for nearly half of all antibiotic prescriptions in primary care, and up to $64 \%$ of these are unnecessary or inappropriate both in the Swiss (41\%) and other settings [6,22,36-39]. In our study, ciprofloxacin and norfloxacin accounted for $85 \%$ of all fluoroquinolone prescriptions. One of the two fluoroquinolones were prescribed to a third of all patients with a UTI diagnosis code. These antibiotics are often inappropriately prescribed for UTIs [21]. Thus, although the overall prescription rates of fluoroquinolones are declining, our study suggests that a relevant proportion of these prescriptions may still be inappropriate.

Our findings by seasonal fluctuation are similar to those both from Swiss [24] and international [40-43] studies showing that antibiotic prescribing is higher in winter than in summer months. Antibiotic consumption during the autumn and winter seasons in the continents of the Northern hemisphere has been demonstrated [44]. In particular, countries with high yearly use of antibiotics show heightened peaks of antibiotic prescribing in winter [5].

\subsection{Factors Associated with Antibiotic Prescribing}

Research shows that a minority of physicians prescribe the majority of antibiotics in the outpatient care setting [45]. Our results confirm this finding showing that the upper quarter of prescribers in our database prescribed almost $43 \%$ of all antibiotics. Results from our regression analysis suggest that more antibiotic prescribing is associated with increased consultation rates, and less prescribing is associated with lower rates of employment. These factors, relating to the amount of workload, are in line with research showing that high practice volume may result in higher (frequent and inappropriate) antibiotic prescribing [46,47]. In our study, RTI and UTIs were the clinical indications most commonly prescribed with antibiotics, which is in line with research showing that GPs with a high practice volume are more likely to (inappropriately) prescribe antibiotics for RTIs overall [46,47] and viral RTIs [48]. Research has also shown that GPs tend to prescribe more when they feel they have less available time per patient [47]. Studies from Europe [47] and Canada [48] show that GPs with longer 'years (of experience) in practice' are more likely to prescribe unnecessary (frequently and inappropriately) antibiotics. In our univariable analysis, however, this factor was not a significant predictor of antibiotic prescribing, which agrees with other Swiss [21,23,49] studies in the GP setting. A sensitivity analysis (results not shown) confirmed that, after correcting for confounding, the rates of antibiotic prescribing were not significantly different by GPs with "no" self-dispensing than by GPs with self-dispensing $(p=0.145)$.

Identification of the patient characteristics that are associated with increased (inappropriate) antibiotic prescriptions is essential too. In our study, patients' increasing age and being a woman increased the likelihood of receiving an antibiotic prescription. In our sensitivity analysis, after excluding patients with UTIs, however, gender was no longer associated with antibiotic prescribing $(p=0.505)$. These findings are in line with previous studies from Europe [50,51], the USA [52], and Australia [53].

\subsection{Strengths and Limitations of the Study}

Our study is the first study in the field assessing the patterns and associated factors of antibiotic prescribing exclusively in the GP setting. Our analysis includes all data available on prescribing of systemic antibiotics regardless of the clinical indication, or whether GPs were low or high prescribers, in contrast with studies assessing the prevalence, predictors, or quality of antibiotic prescribing [21-25]. Moreover, our analysis based on aggregated data over 12 years shows trends of antibiotic prescribing that are similar to those reported by individual prospective studies and the national surveillance, thus supporting the validity of our results.

Our study was limited by a sample that is predominantly representative of the German-speaking area of Switzerland. Compared to sales or health insurance claims data, we could not calculate the 
number of "Defined Daily Doses" (DDDs) per 1000 inhabitants per day as this would depend on patient data that were not uniformly available in our database. Our analysis thus could not provide a more in-depth comparison for the national surveillance data. Finally, the number of GPs collaborating in the FIRE database increased over the last decade, changing the sample size of our study over the observation period. The confidence intervals across the GPs' sample sizes over time were similar and non-significant, however.

\subsection{Implications for Future Research, Policy and Practice}

Several initiatives, both Swiss $[12,31,32]$ and international $[8,13,54]$ have responded to the emergency call from the WHO [10] to contain ABR by establishing surveillance on antibiotic consumption as a central element. As such, tackling inappropriate antibiotic use aims at both quantitative and qualitative aspects [55]. In our study, prescriptions of fluoroquinolones, macrolide and lincosamide declined, although at the expense of their potentially inappropriate use and increased use of BSP. Future health policymaking should consider this quantitative-qualitative phenomenon.

At the national level, several aspects of antibiotic stewardship could be considered to improve antibiotic prescribing in primary care. Continued efforts could help to sustain and further reduce the use of antibiotics in the AWaRe Watch group, fluoroquinolones, macrolide and lincosamides in particular. In addition, specific interventions aiming to halt and reduce the increased use of BSP could be implemented. Using aminopenicillins without BLI is appropriate for many upper RTIs [56,57], for example, but in our study, a combination of penicillin and BLI was prescribed 4.5 more often. The interventions could also target the inequality in antibiotic prescriptions between GPs. Proper identification of "high prescribers" could be crucial to improve antibiotic prescribing [58]. Especially in settings with limited resources, focusing on the group of "high-prescribers" could maximise the impact of future interventions.

Another key factor that future antibiotic stewardship interventions should consider is how gender influences prescribing. Whether this fact is only affected by the tendency in women to seek primary care more often than men [59] needs to be evaluated in further studies. In our study, excluding the patients with UTIs from our analyses showed gender as a non-significant predictor of antibiotic prescribing, which demonstrates that UTIs can be a significant confounding variable of antibiotic prescribing in women in a sample assessing overall antibiotic prescribing.

\section{Materials and Methods}

\subsection{Study Design and Setting}

We conducted a retrospective cross-sectional analysis using data from health EMRs contained in the database of Family Medicine ICPC (International Classification of Primary Care)-Research using EMR (FIRE) [26]. FIRE was established in 2008 and collects anonymised routine patient medical and health data provided by a network of General practitioners (GPs) from the German-speaking area of Switzerland. By April 2020, the database had accumulated data from approximately 550 GPs representing $10.5 \%$ of all registered GPs working in the German-speaking area and comprising more than 780,000 patients with more than 9.4 million consultations.

\subsection{Participants' Inclusion and Exclusion Criteria and Operational Definitions}

We included all FIRE data available from 2008 to April 2020 from patients within the age of $\geq 18$ and $\leq 100$ years and who were prescribed with at least one antibiotic for systemic use. We identified all antibiotic prescriptions within FIRE based on 1) the WHO Anatomical Therapeutic Chemical Classification System (ATC) codes [60] and 2) Swiss pharma codes, which are unique numbers for the identification of a drug and dosage. We selected all systemic antibacterial drugs, antimycobacterials, and drugs with ATC codes specific for intestinal antiinfectives (see Supplementary Materials). We excluded ATC codes of topical antibacterial drugs, antimycotics, and antivirals; and data for which the date of first antibiotic prescription, for a single patient, coincided with the date of first consultations. Research 
using the FIRE database does not require ethical approval since it does not fall under the scope of the Federal Act on Research involving human beings (Human Research Act; Local Ethics Committee of the Canton of Zurich, BASEC-Number: Req-2017-00797).

\subsection{Classification of Antibiotics and Diagnoses}

We grouped all antibiotics according to drug classes and used WHO AWaRe to classify all selected antibiotics [28]. The WHO AWaRe classification consists of three stewardship groups that emphasise the importance of their optimal use and their potential for antibiotic resistance: Access, Watch, and Reserve. Diagnosis codes based on the current ICPC-2 code system [61] were available for a subgroup of patients, and we related these diagnoses to ATC codes.

\subsection{Data Variables and Analysis}

We characterised antibiotic prescriptions by patients and GPs' characteristics (age, gender), canton of GPs' practice, and rates and type of antibiotics by ATC codes and AWaRe class. We calculated the number of patients or events with their corresponding proportions ( $\mathrm{n}$ and \%) to describe categorical data, and the mean, standard deviations (SD) and ranges [min-max] to describe numerical data. We performed subgroup analyses of patient records with available ICPC-2 diagnosis (general and infectious diseases) codes to identify the most common clinical indications for antibiotic prescribing. These analyses used data from two weeks before and two weeks after the first antibiotic prescription to make sure of a connection between the diagnoses and antibiotic prescriptions. We used the Lorenz curve [62] to analyse and describe the (un-)equality in distribution of antibiotic prescriptions among GPs. The Gini coefficient represents the area under the Lorenz curve. It is a measure of deviation from equal distribution. A Gini coefficient ranges from " 0 " to " 1 ", which implies perfect equality or total inequality, respectively. The further the Lorenz curve deviates from perfect equality, the higher the Gini coefficient and the higher the inequality. A recommended interpretation for Gini values includes low inequality for a coefficient of 0.20 and extreme inequality for a coefficient of 0.50 [63].

We performed univariable and multivariable analyses to assess the association between patients' and GPs' characteristics and antibiotic prescribing. We included patients' and GPs' characteristics as predictors or fixed effects including age, gender, number of consultations per year, years in practice, employment level and status, and practice type. We performed linear random-effects mixed model regression analysis at the GP cluster-level. We corrected the model for GP consultations using a dichotomous variable ( $<$ or $\geq 6000$ GP consultations per year). In the multivariable model analysis, we considered relevant effects together by constructing a model using variables with potential relevance for subgroup analyses, and which had a significance level of $p \leq 0.2$ in the univariable analysis. Using stepwise backward elimination, we developed the final multivariable model with the best fit for the outcome of interest. We performed sensitivity analyses to identify potential confounders of antibiotic prescribing using univariable analyses based on the number of prescriptions for the sample of patients with available ICPC codes. We also considered the type of dispensing license in a sensitivity analysis. We present the results as effect estimates with their corresponding 95\% confidence intervals (CI) and intraclass correlation coefficient and report the summary statistics.

We performed all analyses using the statistical software package $\mathrm{R}$ (version 3.6.1) and considered $p<0.05$ statistically significant for all tests [64]. For all analyses with specific GPs' characteristics (e.g., age, gender, years in practice, consultations, type of practice), we used a validated dataset from 2018 [65] since differentiation between single and group GP practices is not yet possible in our database.

\section{Conclusions}

In Swiss (German-speaking) general practice, RTIs, UTIs and skin infections are the most common clinical indications prescribed with antibiotics. Amoxicillin plus BLI, ciprofloxacin and clarithromycin are the most commonly prescribed antibiotics. In keeping with national and European surveillance, we found a decline in prescriptions of fluoroquinolones, macrolides and lincosamides, however, at the 
expense of their potentially inappropriate use and increased use of BSP. Several patients and GPs' characteristics were associated with antibiotic prescribing. Health policy initiatives engaged in antibiotic stewardship could use these findings to inform future interventions tailored to the factors associated with antibiotic prescribing.

Supplementary Materials: Additional supporting material is contained in the Supplementary Materials and it is available online at http://www.mdpi.com/2079-6382/9/11/837/s1. Table S1: Full list of all antibiotic prescriptions in Swiss primary care; Table S2: Gender distribution for quinolone prescriptions.

Author Contributions: Conceptualization, N.A.M.-G., S.N.-J., O.S. and A.P.; data curation, G.P.; formal analysis, S.D.G.; investigation, N.A.M.-G. and A.P.; methodology, N.A.M.-G. and A.P.; validation, G.P.; visualization, S.D.G. and G.P.; writing—original draft, N.A.M.-G. and A.P.; writing—review and editing, N.A.M.-G., S.N.-J., O.S. and A.P. All authors take responsibility for appropriate content, critically revised the manuscript, and approved the version of the manuscript to be published.

Funding: This research received no external funding.

Acknowledgments: We thank the FIRE study group of general practitioners for their participation in the project. We also thank Fabio Valeri and Stefan Zechmann for the discussions in the planning stage of this study.

Conflicts of Interest: The authors declare no conflict of interest.

\section{References}

1. Cassini, A.; Högberg, L.D.; Plachouras, D.; Quattrocchi, A.; Hoxha, A.; Simonsen, G.S.; Colomb-Cotinat, M.; Kretzschmar, M.E.; Devleesschauwer, B.; Cecchini, M.; et al. Attributable deaths and disability-adjusted life-years caused by infections with antibiotic-resistant bacteria in the eu and the european economic area in 2015: A population-level modelling analysis. Lancet Infect. Dis. 2019, 19, 56-66. [CrossRef]

2. World Health Organization. Antimicrobial Resistance: Global Report on Surveillance; WHO: Geneva, Switzerland, 2014.

3. Costelloe, C.; Metcalfe, C.; Lovering, A.; Mant, D.; Hay, A.D. Effect of antibiotic prescribing in primary care on antimicrobial resistance in individual patients: Systematic review and meta-analysis. BMJ 2010, 340, c2096. [CrossRef] [PubMed]

4. $\quad$ Hicks, L.A.; Bartoces, M.G.; Roberts, R.M.; Suda, K.J.; Hunkler, R.J.; Taylor, T.H., Jr.; Schrag, S.J. Us outpatient antibiotic prescribing variation according to geography, patient population, and provider specialty in 2011. Clin. Infect. Dis. 2015, 60, 1308-1316. [CrossRef] [PubMed]

5. Goossens, H.; Ferech, M.; Vander Stichele, R.; Elseviers, M. Outpatient antibiotic use in europe and association with resistance: A cross-national database study. Lancet 2005, 365, 579-587. [CrossRef]

6. Fleming-Dutra, K.E.; Hersh, A.L.; Shapiro, D.J.; Bartoces, M.; Enns, E.A.; File, T.M., Jr.; Finkelstein, J.A.; Gerber, J.S.; Hyun, D.Y.; Linder, J.A.; et al. Prevalence of inappropriate antibiotic prescriptions among us ambulatory care visits, 2010-2011. JAMA 2016, 315, 1864-1873. [CrossRef] [PubMed]

7. Klein, E.Y.; Van Boeckel, T.P.; Martinez, E.M.; Pant, S.; Gandra, S.; Levin, S.A.; Goossens, H.; Laxminarayan, R. Global increase and geographic convergence in antibiotic consumption between 2000 and 2015. Proc. Natl. Acad. Sci. USA 2018, 115, e3463-e3470. [CrossRef]

8. European Center for Disease Prevention and Control. Surveillance and disease data for antimicrobial consumption. Available online: https://www.Ecdc.Europa.Eu/en/antimicrobial-consumption/surveillanceand-disease-data (accessed on 17 September 2020).

9. Interagency Coordination Group (IACG) on Antimicrobial Resistance. No time to wait: Securing the future from drug-resistant infections: Report to the secretary-general of the united nations. April 2019. Available online: https://www.Who.Int/docs/default-source/documents/no-time-to-wait-securing-the-future-fromdrug-resistant-infections-en.Pdf?Sfvrsn=5b424d7_6 (accessed on 7 July 2020).

10. World Health Organization. Global action plan on antimicrobial resistance; WHO: Geneva, Switzerland, 2015.

11. Adriaenssens, N.; Coenen, S.; Versporten, A.; Muller, A.; Vankerckhoven, V.; Goossens, H. European surveillance of antimicrobial consumption (esac): Quality appraisal of antibiotic use in europe. J. Antimicrob. Chemother. 2011, 66, vi71-vi77. [CrossRef] [PubMed]

12. Swiss Centre for Antibiotic Resistance-Anresis.ch. Meldungen Ausgewählter Multiresistenter Mikroorganismen in der Schweiz. Bern, Switzerland. In Informationsmagazin für Medizinische Fachpersonen und Medienschaffende; Bundesamt für Gesundheit BAG: Bern, Switzerland, 2020; pp. 8-9. Available online: http://www.anresis.ch (accessed on 11 August 2020). 
13. Centers for Disease Control and Prevention. Antibiotic use in outpatient settings, 2017: Antibiotic use by healthcare setting. Available online: https://www.Cdc.Gov/antibiotic-use/stewardship-report/outpatient. Html (accessed on 17 September 2020).

14. King, L.M.; Fleming-Dutra, K.E.; Hicks, L.A. Advances in optimizing the prescription of antibiotics in outpatient settings. BMJ 2018, 363, k3047. [CrossRef]

15. ANRESIS. Swiss Antibiotic Resistance Report 2018: Usage of Antibiotics and Occurrence of Antibiotic Resistance in Bacteria from Humans and Animals in Switzerland. Available online: https://www. Bundespublikationen.Admin.Ch/cshop_mimes_bbl/8c/8cdcd4590ee41ed8b9c944668445697e.Pdf (accessed on 17 September 2020).

16. Federal Office of Public Health (FOPH). What is the Total Consumption of Antibiotics? Available online: https://www.Bag.Admin.Ch/bag/en/home/krankheiten/infektionskrankheiten-bekaempfen/ antibiotikaresistenzen/wie-entwickelt-sich-die-antibiotikaresistenzlage-.Html (accessed on 7 July 2020).

17. European Centre for Disease Prevention and Control (ECDC). Summary of the Latest Data on Antibiotic Consumption in the European Union. Esac-net surveillance data. Available online: https://www.Ecdc.Europa. Eu/en/publications-data/summary-latest-data-antibiotic-consumption-eu-2018 (accessed on 11 August 2020).

18. Schweizerische Gesundheitsobservatorium (Obsan). Ärztinnen und Ärzte in Freier Praxis. Dichte der Ärztinnen und Ärzte in Freier Praxis-2017. Available online: Https://www.Obsan.Admin.Ch/de/indikatoren/ aerztinnen-und-aerzte-freier-praxis (accessed on 11 August 2020).

19. Zweigner, J.; Meyer, E.; Gastmeier, P.; Schwab, F. Rate of antibiotic prescriptions in german outpatient care-Are the guidelines followed or are they still exceeded? GMS Hyg. Infect. Control 2018, 13, Doc04.

20. Edelstein, M.; Agbebiyi, A.; Ashiru-Oredope, D.; Hopkins, S. Trends and patterns in antibiotic prescribing among out-of-hours primary care providers in England, 2010-14. J. Antimicrob. Chemother. 2017, 72, 3490-3495. [CrossRef]

21. Plate, A.; Kronenberg, A.; Risch, M.; Mueller, Y.; Di Gangi, S.; Rosemann, T.; Senn, O. Treatment of urinary tract infections in swiss primary care: Quality and determinants of antibiotic prescribing. BMC Fam. Pract. 2020, 21, 125. [CrossRef] [PubMed]

22. Glinz, D.; Leon Reyes, S.; Saccilotto, R.; Widmer, A.F.; Zeller, A.; Bucher, H.C.; Hemkens, L.G. Quality of antibiotic prescribing of swiss primary care physicians with high prescription rates: A nationwide survey. J. Antimicrob. Chemother. 2017, 72, 3205-3212. [CrossRef] [PubMed]

23. Streit, S.; Frey, P.; Singer, S.; Bollag, U.; Meli, D.N. Clinical and haematological predictors of antibiotic prescribing for acute cough in adults in swiss practices-An observational study. BMC Fam. Pract. 2015, 16, 15. [CrossRef] [PubMed]

24. Achermann, R.; Suter, K.; Kronenberg, A.; Gyger, P.; Muhlemann, K.; Zimmerli, W.; Bucher, H.C. Antibiotic use in adult outpatients in switzerland in relation to regions, seasonality and point of care tests. Clin. Microbiol. Infect. 2011, 17, 855-861. [CrossRef]

25. Briel, M.; Young, J.; Tschudi, P.; Hersberger, K.E.; Hugenschmidt, C.; Langewitz, W.; Bucher, H.C. Prevalence and influence of diagnostic tests for acute respiratory tract infections in primary care. Swiss Med. Wkly. 2006, 136, 248-253.

26. Chmiel, C.; Bhend, H.; Senn, O.; Zoller, M.; Rosemann, T. The fire project: A milestone for research in primary care in switzerland. Swiss Med. Wkly. 2011, 140, w13142.

27. European Center for Disease Prevention and Control. Surveillance Report: Antimicrobial Consumption in the eu/eea, Annual Epidemiological Report for 2018: Distribution by Antimicrobiall Group. Available online: https://www.Ecdc.Europa.Eu/en/antimicrobial-consumption/database/distribution-by-antimicrobialgroup (accessed on 20 September 2020).

28. World Health Organisation. Aware-A New Who Tool to Help Countries Improve Antibiotic Treatment, Increase Access and Reduce Resistance. 2019. Available online: https://adoptaware.Org/ (accessed on 11 August 2020).

29. European Center for Disease Prevention and Control. Surveillance Report: Antimicrobial Consumption in the eu/eea, Annual Epidemiological Report for 2018: Trend of Antimicrobial Consumption by Country. Available online: https://www.Ecdc.Europa.Eu/en/antimicrobial-consumption/database/trend-country (accessed on 17 September 2020). 
30. Public Health England. English Surveillance Programme for Antimicrobial Utilisation and Resistance (espaur). Report 2018-2019. Available online: https://www.Gov.Uk/government/publications/english-surveillanceprogramme-antimicrobial-utilisation-and-resistance-espaur-report (accessed on 20 September 2020).

31. Selby, K.; Gaspoz, J.-M.; Rodondi, N.; Neuner-Jehle, S.; Perrier, A.; Zeller, A.; Cornuz, J. Creating a list of low-value health care activities in swiss primary care. JAMA Intern. Med. 2015, 175, 640-642. [CrossRef]

32. Federal Office of Public Health and Federal Food Safety and Veterinary Office and the Strategy on Antibiotic Resistance (StAR). Swiss Antibiotic Resistance Report 2018. Usage of antibiotics And Occurrence of Antibiotic Resistance in Bacteria from Humans and Animals in Switzerland. 2018. Available online: http://www.Anresis. Ch/files/pdf/bag_swiss_antibiotic_resistance_report_2016_web.pdf (accessed on 11 August 2020).

33. Shively, N.R.; Buehrle, D.J.; Clancy, C.J.; Decker, B.K. Prevalence of inappropriate antibiotic prescribing in primary care clinics within a veterans affairs health care system. Antimicrob. Agents Chemother. 2018, 62, e00337-18. [CrossRef]

34. Petersen, I.; Hayward, A.C. Antibacterial prescribing in primary care. J. Antimicrob. Chemother. 2007, 60, i43-i47. [CrossRef]

35. DemoSCOPE. Survey on Antimicrobial Resistance Commissioned by the Federal Office of Public Health. September 2016. Available online: https:/www.Star.Admin.Ch/star/en/home/star/brennpunkte/brennpunktzwei.Html (accessed on 7 June 2020).

36. Havers, F.P.; Hicks, L.A.; Chung, J.R.; Gaglani, M.; Murthy, K.; Zimmerman, R.K.; Jackson, L.A.; Petrie, J.G.; McLean, H.Q.; Nowalk, M.P.; et al. Outpatient antibiotic prescribing for acute respiratory infections during influenza seasons. JAMA Netw. Open 2018, 1, e180243. [CrossRef]

37. Dekker, A.R.; Verheij, T.J.; van der Velden, A.W. Inappropriate antibiotic prescription for respiratory tract indications: Most prominent in adult patients. Fam. Pract. 2015, 32, 401-407. [CrossRef] [PubMed]

38. Schroeck, J.L.; Ruh, C.A.; Sellick, J.A., Jr.; Ott, M.C.; Mattappallil, A.; Mergenhagen, K.A. Factors associated with antibiotic misuse in outpatient treatment for upper respiratory tract infections. Antimicrob. Agents Chemother. 2015, 59, 3848-3852. [CrossRef]

39. Gebeyehu, E.; Bantie, L.; Azage, M. Inappropriate use of antibiotics and its associated factors among urban and rural communities of bahir dar city administration, northwest ethiopia. PLoS ONE 2015, 10, e0138179. [CrossRef] [PubMed]

40. Elseviers, M.M.; Ferech, M.; Vander Stichele, R.H.; Goossens, H. Antibiotic use in ambulatory care in europe (esac data 1997-2002): Trends, regional differences and seasonal fluctuations. Pharmacoepidemiol. Drug Saf. 2007, 16, 115-123. [CrossRef] [PubMed]

41. Ferech, M.; Coenen, S.; Malhotra-Kumar, S.; Dvorakova, K.; Hendrickx, E.; Suetens, C.; Goossens, H. European surveillance of antimicrobial consumption (esac): Outpatient antibiotic use in europe. J. Antimicrob. Chemother. 2006, 58, 401-407. [CrossRef]

42. Suda, K.J.; Hicks, L.A.; Roberts, R.M.; Hunkler, R.J.; Taylor, T.H. Trends and seasonal variation in outpatient antibiotic prescription rates in the united states, 2006 to 2010. Antimicrob. Agents Chemother. 2014, 58, 2763-2766. [CrossRef]

43. Curtis, H.J.; Walker, A.J.; Mahtani, K.R.; Goldacre, B. Time trends and geographical variation in prescribing of antibiotics in england 1998-2017. J. Antimicrob. Chemother. 2018, 74, 242-250. [CrossRef]

44. Van Boeckel, T.P.; Gandra, S.; Ashok, A.; Caudron, Q.; Grenfell, B.T.; Levin, S.A.; Laxminarayan, R. Global antibiotic consumption 2000 to 2010: An analysis of national pharmaceutical sales data. Lancet Infect. Dis. 2014, 14, 742-750. [CrossRef]

45. Jones, B.E.; Sauer, B.; Jones, M.M.; Campo, J.; Damal, K.; He, T.; Ying, J.; Greene, T.; Goetz, M.B.; Neuhauser, M.M.; et al. Variation in outpatient antibiotic prescribing for acute respiratory infections in the veteran population: A cross-sectional study. Ann. Intern. Med. 2015, 163, 73-80. [CrossRef]

46. Gjelstad, S.; Straand, J.; Dalen, I.; Fetveit, A.; Strøm, H.; Lindbæk, M. Do general practitioners' consultation rates influence their prescribing patterns of antibiotics for acute respiratory tract infections? J. Antimicrob. Chemother. 2011, 66, 2425-2433. [CrossRef]

47. Akkerman, A.E.; Kuyvenhoven, M.M.; van der Wouden, J.C.; Verheij, T.J. Prescribing antibiotics for respiratory tract infections by gps: Management and prescriber characteristics. Br. J. Gen. Pract. 2005, 55, 114-118. [PubMed]

48. Cadieux, G.; Tamblyn, R.; Dauphinee, D.; Libman, M. Predictors of inappropriate antibiotic prescribing among primary care physicians. Cmaj. 2007, 177, 877-883. [CrossRef] [PubMed] 
49. Selby, K.; Cornuz, J.; Cohidon, C.; Gaspoz, J.-M.; Senn, N. How do swiss general practitioners agree with and report adhering to a top-five list of unnecessary tests and treatments? Results of a cross-sectional survey. Eur. J. Gen. Pract. 2018, 24, 32-38. [CrossRef] [PubMed]

50. Saliba-Gustafsson, E.A.; Dunberger Hampton, A.; Zarb, P.; Orsini, N.; Borg, M.A.; Stålsby Lundborg, C. Factors associated with antibiotic prescribing in patients with acute respiratory tract complaints in malta: A 1-year repeated cross-sectional surveillance study. BMJ Open 2019, 9, e032704. [CrossRef] [PubMed]

51. Haeseker, M.B.; Dukers-Muijrers, N.H.T.M.; Hoebe, C.J.P.A.; Bruggeman, C.A.; Cals, J.W.L.; Verbon, A. Trends in antibiotic prescribing in adults in dutch general practice. PLoS ONE 2012, 7, e51860. [CrossRef] [PubMed]

52. Lee, G.C.; Reveles, K.R.; Attridge, R.T.; Lawson, K.A.; Mansi, I.A.; Lewis, J.S.; Frei, C.R. Outpatient antibiotic prescribing in the united states: 2000 to 2010. BMC Med. 2014, 12, 96. [CrossRef]

53. Dallas, A.; Magin, P.; Morgan, S.; Tapley, A.; Henderson, K.; Ball, J.; Scott, J.; Spike, N.; McArthur, L.; van Driel, M. Antibiotic prescribing for respiratory infections: A cross-sectional analysis of the recent study exploring the habits of early-career doctors in primary care. Fam. Pract. 2014, 32, 49-55. [CrossRef]

54. The White House. National Action Plan for Combating Antibiotic-Resistant Bacteria. 2015: Washington. Available online: https://obamawhitehouse.Archives.Gov/sites/default/files/docs/national_action_plan_for_ combating_antibotic-resistant_bacteria.Pdf (accessed on 11 August 2020).

55. Tamma, P.D.; Miller, M.A.; Cosgrove, S.E. Rethinking how antibiotics are prescribed: Incorporating the 4 moments of antibiotic decision making into clinical practice. JAMA 2019, 321, 139-140. [CrossRef]

56. Guideline: Akute Bakterielle Sinusitis (d). Available online: https://ssi.Guidelines.Ch/guideline/2410 (accessed on 17 September 2020).

57. Guideline: Pharyngitis (d). Available online: https://ssi.Guidelines.Ch/guideline/240 (accessed on 20 September 2020).

58. Patel, A.; Pfoh, E.R.; Misra Hebert, A.D.; Chaitoff, A.; Shapiro, A.; Gupta, N.; Rothberg, M.B. Attitudes of high versus low antibiotic prescribers in the management of upper respiratory tract infections: A mixed methods study. J. Gen. Intern. Med. 2020, 35, 1182-1188. [CrossRef]

59. Smith, D.R.M.; Dolk, F.C.K.; Smieszek, T.; Robotham, J.V.; Pouwels, K.B. Understanding the gender gap in antibiotic prescribing: A cross-sectional analysis of english primary care. BMJ Open 2018, 8, e020203. [CrossRef]

60. WHO Collaborating Centre for Drug Statistics Methodology. Guidelines for the Anatomical Therapeutic Chemical Classification (atc) and Defined Daily Doses (ddd) Assignment 2020; WHO Collaborating Centre for Drug Statistics Methodology: Oslo, Norway, 2019.

61. Who International Classification of Primary Care, Second Edition (icpc-2). Available online: http://www. Who.Int/classifications/icd/adaptations/icpc2/en/ (accessed on 9 May 2020).

62. Lorenz, M.O. Methods of measuring the concentration of wealth. Publ. Am. Stat. Assoc. 1905, 9, $209-219$. [CrossRef]

63. Luebnker, M. Inequality, Income Shares and Poverty: The Practical Meaning of Gini Coefficients. In Travail Policy Brief no. 3. June 2010. Conditions of Work and Employment Programme (Travail), International Labour Office. Available online: https://www.Ilo.Org/wcmsp5/groups/public/-ed_protect--protrav/-travail/ documents/publication/wcms_145695.Pdf (accessed on 20 September 2020).

64. R core team. R: A language and environment for statistical computing. In R foundation for Statistical Computing, Editor; R core team: Vienna, Austria, 2018.

65. Rachamin, Y.; Meier, R.; Grischott, T.; Rosemann, T.; Markun, S. General practitioners' consultation counts and associated factors in swiss primary care-A retrospective observational study. PLoS ONE 2019, 14, e0227280. [CrossRef] [PubMed]

Publisher's Note: MDPI stays neutral with regard to jurisdictional claims in published maps and institutional affiliations. 